\title{
REVIEW LITERATUR: STRATEGI GURU BIMBINGAN DAN KONSELING DALAM MENGATASI KENAKALAN SISWA DI SEKOLAH
}

\author{
Rindra Risdiantoro ${ }^{1)}$ \\ 1)Institut Agama Islam Sunan Kalijogo Malang \\ 1)rindrasutoro@gmail.com
}

\begin{abstract}
Abstrak. Kenakalan siswa terjadi sebagai aktualisasi dari keadaan jiwa dan kebutuhan tetapi berdampak negatif. Guru BK bertanggung jawab mengatasi masalah kenakalan siswa. Pelayanan bimbingan dan konseling sangat penting untuk dilaksanakan guna membantu siswa mengatasi berbagai masalah yang dihadapi. Review ini bertujuan untuk: mengidentifikasi bentuk-bentuk kenakalan siswa di sekolah, menjelaskan faktor yang mempengaruhi kenakalan siswa, menjelaskan strategi guru dalam mengatasi kenakalan siswa. Hasil review yaitu 1) bentuk-bentuk kenakalan siswa terdiri dari kenakalan kategori ringan seperti: membolos, ramai sewaktu pelajaran berlangsung, tidak mengerjakan tugas, seragam tidak lengkap, ke kantin saat pelajaran, bermain HP saat pelajaran, membantah guru dan orang tua, sedangkan kenakalan kategori berat seperti: mencuri, perkelahian, narkoba, asusila, 2) faktor yang mempengaruhi kenakalan siswa adalah lingkungan keluarga dan lingkungan pergaulan di masyarakat, 3) strategi guru dalam mengatasi kenakalan siswa di sekolah yaitu strategi dalam pembelajaran berupa pembiasaan dan modeling, strategi tindakan dalam bentuk preventif, preservatif dan kuratif.
\end{abstract}

Kata Kunci: Strategi, Guru BK, Kenakalan siswa

\begin{abstract}
Student delinquency occurs as an actualization of mental states and needs but has a negative impact. The teacher is responsible for dealing with student delinquency problems. Guidance and counseling services are very important to be implemented in order to help students overcome various problems faced. This review aims to: identify forms of student delinquency in schools, explain the factors that influence student delinquency, explain teacher strategies in overcoming student delinquency. The results of the review were 1) the forms of student delinquency consisted of mild delinquency such as truancy, being busy during lessons, not doing assignments, incomplete uniforms, going to the canteen during lessons, playing handphone during lessons, arguing against teachers and parents, while naughtiness heavy categories such as: stealing, fighting, drugs, immorality, 2) the factors that influence student delinquency are the family environment and social environment in the community, 3) the teacher's strategy in overcoming student delinquency in schools, namely strategies in
\end{abstract}




\section{Al-Isyrof \\ Jurnal Bimbingan Konseling Islam}

Institut Agama Islam Sunan Kalijogo Malang

P-ISSN 2622-674X / E-ISSN 2721-9585

Volume 2, Nomer 1 / Juni 2020

learning in the form of habituation and modeling, action strategies in the form of preventive, preservative and curative.

Keywords: Strategy, BK Teachers, Student Delinquency.

\section{PENDAHULUAN}

Kenakalan siswa bukanlah hal baru. Masalah ini sering terjadi disetiap hari. Kenakalan siswa karena pengaruh lingkungan, kebudayaan dan masyarakat. ${ }^{1}$ Kenakalan yang terjadi pada siswa merupakan hal yang wajar karena kondisi yang ada pada siswa cenderung masih labil sehingga masih diombang-ambingkan oleh segala sesuatu yang ada di sekitar. Kenakalan yang dilakukan dapat dikatakan sebagai aktualisasi dari keadaan jiwa dan kebutuhan yang diinginkan, akan tetapi kesemuanya itu tidak mungkin terjadi dengan sendirinya tanpa ada faktor yang mempengaruhinya. ${ }^{2}$

Kenakalan siswa bisa diartikan sebagai suatu kelalaian tingkah laku, perbuatan atau tindakan yang bersifat asosial yang melanggar norma-norma dalam masyarakat. Ditinjau dari segi agama, jelas sudah bahwa apa yang dilarang dan apa yang disuruh oleh agama. Semua yang dianggap oleh umum sebagai perbuatan nakal adalah hal-hal yang dilarang agama. Kenakalan adalah suatu penyimpangan tingkah laku yang dilakukan hingga menggangu ketentraman diri sendiri dan orang lain. Kenakalan siswa adalah ungkapan dari ketegangan perasaan, kegelisahan dan kecemasan atau tekanan batin sebagai respon terhadap pengaruh dari lingkungan sekitar. ${ }^{3}$

Semua tindakan siswa dibatasi oleh aturan atau norma untuk berbuat dan berprilaku sesuai dengan sesuatu yang dianggap baik oleh masyarakat. Penyimpangan terhadap norma-norma atau nilai-nilai disebut deviasi, sedangkan

\footnotetext{
1 Ibnudin, "Konsep Bimbingan dan Konseling dalam Mengatasi Kenakalan Siswa (Studi Kasus di MTs AlGozali Jatibarang Kabupaten Indramayu)", Al-Afkar: Journal for Islamic Studies, Vol. 2, No. 2, (Juli 2019), 126.

2 Muhamad Ghafur dan Dhuhaa Rohmawan, "Strategi Pembelajaran Afektif Guru PAI dalam Menanggulangi Kenakalan Siswa Di SMK Brawijaya Kepung Kediri”, Inovatif, Vol. 1, No. 2 (September 2015), 95.

${ }^{3}$ Ibid, 102.
} 


\section{Al-Isurof \\ Jurnal Bimbingan Konseling Islam}

Institut Agama Islam Sunan Kalijogo Malang

P-ISSN 2622-674X / E-ISSN 2721-9585

Volume 2, Nomer 1 / Juni 2020

pelaku atau individu yang melakukan penyimpangan disebut devian. Kebalikan dari prilaku menyimpang adalah prilaku yang tidak menyimpang, sering disebut dengan konformitas. Konformitas adalah bentuk interaksi sosial yang didalamnya seseorang berprilaku sesuai dengan keinginan dan harapan kelompok. ${ }^{4}$ Perilaku siswa dibentuk untuk konformitas sehingga tujuan dari pendidikan dapat tercapai.

Kenakalan siswa jika dibiarkan berdampak negatif pada akhirnya akan terbawa sampai ke kehidupan dewasanya. Masalah ini dikhawatirkan dapat mengganggu proses perkembangan diri dan belajar mengajar siswa di sekolah. Upaya sekolah dalam menangani permasalahan ini menjadi peran utama. Sebagai perencanaan, pelaksanaan, pengelolaan, pengendalian, menjadi pelapor dari hasil pelaksanaan layanannya. Bimbingan dan Konseling merupakan bagian integral dalam program pendidikan. Bimbingan membantu agar proses pendidikan berjalan dengan efesien, dalam arti cepat dan mudah. Bimbingan berfokus pada bidang masalah yang dihadapi atau dialami oleh individu sebagai bidang operasinya. ${ }^{5}$ Bimbingan juga dilakukan mengembangkan segala potensi positif yang mereka miliki seperti bakat, kemampuan, dan minat serta diberi bimbingan agama agar menjadi pedoman hidup baginya. ${ }^{6}$

Guru BK memiliki tanggung jawab yang besar membantu siswa agar berhasil, untuk itu sekolah memberikan bantuan kepada siswa untuk mengatasi masalah-masalah yang timbul dalam perilaku dan kegiatan belajar siswa. Pelayanan bimbingan dan konseling sangat penting untuk dilaksanakan guna membantu siswa mengatasi berbagai masalah yang dihadapinya. Kehadiran guru bimbingan dan konseling diharapkan untuk dapat membimbing siswa menjadi manusia yang dewasa, susila dan cakap. Tanpa bimbingan siswa akan mengalami

4 La Hadisi, "Pendidikan Agama Islam: Solusi Mengatasi Perilaku Menyimpang Siswa SMK Negeri 1 Kendari", Al-Izzah, Vol. 8, No. 2, (November 2013), 126.

5 Limon, Bimbingan dan Dasar-Dasar Pelaksanaannya, (Jakarta: Rajawali, 2011), 103.

6 Ibnudin, "Konsep Bimbingan dan Konseling dalam Mengatasi Kenakalan Siswa (Studi Kasus di MTs AlGozali Jatibarang Kabupaten Indramayu)", Al-Afkar, Journal for Islamic Studies, Vol. 2, No. 2, (Juli 2019), 127. 
kesulitan dalam menghadapi perkembangan dirinya dan pembelajaran. Oleh karena itu diperlukan strategi-strategi dalam melakukan pembinaan terhadap perilaku siswa.

Strategi adalah proses penentuan rencana pemimpin puncak berfokus pada tujuan jangka panjang, disertai penyusunan upaya bagaimana agar tujuan dapat dicapai. Strategi diartikan sebagai rencana yang cermat atau siasat mengenai kegiatan untuk mencapai sasaran yang khusus. Strategi disusun untuk mencapai tujuan tertentu, dengan demikian penyusunan langkah-langkah pelayanan, pemanfaatan berbagai fasilitas dan sumber belajar semuanya di arahkan dalam upaya pencapaian tujuan. Tujuan yang jelas dapat di ukur keberhasilannya. ${ }^{7}$

Strategi guru bimbingan dan konseling yang jelas dan terukur sangat dibutuhkan dalam mengatasi kenakalan siswa di sekolah. Review ini bertujuan untuk: 1) mengidentifikasi bentuk-bentuk kenakalan siswa di sekolah, 2) menjelaskan faktor yang mempengaruhi kenakalan siswa, 3) menjelaskan strategi guru dalam mengatasi kenakalan siswa di sekolah.

\section{METODE PENELITIAN}

Penelitian ini berfokus pada peran guru bimbingan dan konseling dalam mengatasi kenakalan siswa di sekolah, maka jenis penelitian ini menggunakan penelitian deskriptif kualitatif. Maka teknik pengumpulan data pada penelitian ini adalah metode observasi, wawancara, dan dokumentasi. Observasi adalah mengamati dengan melakukan pencatatan atas kejadian-kejadian yang dilakukan oleh sumber data. Adapun beberapa jenis observasi yang bisa digunakan, yaitu: 1) observasi partisipatif, 2) obsevasi terus terang atau tersamarkan dan 3) observasi tak berstruktur. Tetapi dalam penelitian ini hanya menggunakan observasi partisipasi saja yaitu peneliti datang langsung ke tempat yang akan diamati, dan melakukan pengamatan tanpa ikut serta dalam kegiatan.

${ }^{7}$ Abudin Nata, Perspektif Islam tentang Strategi Pembelajaran, (Jakarta: Kencana, 2009), 203. 


\section{Al-Isurof \\ Jurnal Bimbingan Konseling Islam}

Institut Agama Islam Sunan Kalijogo Malang

P-ISSN 2622-674X / E-ISSN 2721-9585

Volume 2, Nomer 1 / Juni 2020

\section{HASIL DAN PEMBAHASAN}

\section{Bentuk-bentuk Kenakalan Siswa di Sekolah}

Bentuk-bentuk kenakalan siswa berbeda-beda secara umum dibedakan menjadi dua yaitu kenakalan ringan dan kenakalan berat.

1. Kenakalan siswa dalam kategori ringan

Kenakalan yang dilakukan siswa kategori ringan seperti: membolos, ramai sewaktu pelajaran berlangsung, tidak mengerjakan tugas, seragam tidak lengkap, ke kantin saat pelajaran, bermain HP saat pelajaran, membantah guru dan orang tua, melompat pagar sekolah, merokok, mengganggu orang lain. ${ }^{8}$ Kenakalan ringan diantaranya tidak patuh pada orang tua, lari atau bolos dari sekolah, cara berpakaian, dll.

Menurut pendapat yang lain bentuk-bentuk kenakalan ringan siswa di sekolah di antaranya adalah merokok, pacaran, sering bolos sekolah, tidak disiplin. ${ }^{9}$ Pelanggaran terhadap peraturan tata tertib sekolah, pelanggaran terhadap kegiatan belajar mengajar, pelanggaran terhadap ketenteraman sekolah, dan pelanggaran terhadap etika pergaulan dengan warga sekolah seperti: saat jam belajar bermain di sekolah lain, melompat pagar sekolah, membongkar kantin sekolah dan mengambil beberapa botol air mineral, berkelahi di dalam kelas, membawa HP ke sekolah, bolos saat jam belajar, mengganggu anak perempuan, berbicara kotor, melawan guru, dan main bola keluar sekolah, merokok di lokasi sekolah, masuk ke kelas lain untuk mengganggu temannya yang sedang belajar, keluar lewat jendela, bermain-main saat pembelajaran. ${ }^{10}$

8 Winarno Surakmad, Psikologi Pemuda, (Bandung : Jenmars, 1997), 12-13

${ }^{9}$ Firad Wijaya, "Konseling Individual dalam Mengatasi Kenakalan Siswa di Madrasah Tsanawiyah Negeri 1 Yogyakarta”, Al-Tazkiah, Vol. 6, No. 2, (Desember 2017), 99.

10 Nurul Qomariyah Ahmad, Asdiana dan Seni Jayatimar, "Upaya Guru Pendidikan Agama Islam dalam Menghadapi Kenakalan Remaja Pada Masa Pubertas", Jurnal As-Salam, Vol. 3 No. 2, (Mei - Agustus 2019), 9-17. 


\section{Al-Isurof \\ Jurnal Bimbingan Konseling Islam}

Institut Agama Islam Sunan Kalijogo Malang

P-ISSN 2622-674X / E-ISSN 2721-9585

Volume 2, Nomer 1 / Juni 2020

2. Kenakalan siswa dalam kategori berat

Kenakalan yang termasuk dalam kategori berat yaitu: ${ }^{11}$

a. Kenakalan yang menimbulkan korban fisik pada orang lain, seperti: perkelahian, pemerkosaan, perampokan, pembunuhan dan lain-lain.

b. Kenakalan yang menimbulkan korban materi seperti: perusakan, pencurian, pencopetan, pemerasan, dan lain-lain.

c. Kenakalan sosial yang tidak menimbulkan korban dpihak orang lain seperti: pelacuran, penyalahgunaan obat dan juga hubungan seks sebelum menikah.

Menurut pendapat yang lain kenakalan siswa yang dilakukan dalam kategori berat yaitu ${ }^{12}$ kenakalan yang menggangu ketentraman orang lain, yaitu: mencuri, menodong, kebut-kebutan, minum-minuman keras, penyalahgunaan narkotika, meminta sesuatu secara paksa kepada teman yang lain (penargetan), berkelahi antar siswa, pelecehan seksual, terlibat pergaulan bebas. ${ }^{13}$

Kenakalan ringan merupakan awal dari kenakalan berat. Perbuatan awal pencurian meliputi perbuatan berkata bohong dan tidak jujur, perkelahian antar siswa termasuk juga tawuran antar pelajar, mengganggu teman, memusuhi orang tua dan saudara, meliputi perbuatan berkata kasar dan tidak hormat pada orang tua dan saudara, merokok merupakan perbuatan awal dari menghisap ganja, menonton pornografi merupakan perbuatan awal dari pelecehan seksual dan asusial dan perilaku vandalisme meliputi perusakan fasilitas sekolah. ${ }^{14}$

\footnotetext{
11 Sarlito Wirawan Sarwono, Psikologi Remaja, (Jakarta: Rajawali Pres, 1991), 200-201

12 Muhamad Ghafur dan Dhuhaa Rohmawan, "Strategi Pembelajaran Afektif Guru PAI dalam Menanggulangi Kenakalan Siswa Di SMK Brawijaya Kepung Kediri”, Inovatif, Vol. 1, No. 2, (September 2015), 104.

13 Rudi Hartono, Upaya Sekolah dalam Mengatasi Kenakalan Siswa Di SMP Negeri 35 Bengkulu Utara Kabupaten Bengkulu Utara", An-Nizom, Vol. 2, No. 3, (Desember 2017), 530.

14 Loc.cit., Nurul Qomariyah Ahmad, Asdiana dan Seni Jayatimar, 9.
} 


\section{Faktor Penyebab terjadinya Kenakalan Siswa}

1. Faktor lingkungan keluarga

Faktor yang menyebabkan terjadinya kenakalan siswa dalam keluarga antara lain: kurang pendidikan dari orang tua, kurang pengertian orang tua tentang pendidikan, kurang teraturnya pengisian waktu${ }^{15}$. Kebiasaan dalam penyusaian dirinya dengan lingkungan dimana individu itu tinggal, kedudukan dalam keluargayang dimaksudkan adalah urutan-urutan kelahiran. Anak pertama lebih berpotensi nakal dibandingkan dengan anak bungsu. Lingkungan keluarga merupakan wadah yang pertama-tama dan merupakan dasar yang fundamental bagi perkembangan dan pertumbuhan anak. Kebiasaan dan way of life orang tua memberikan warna dasar terhadap pembentuka kepribadian anak. ${ }^{16}$

Faktor keluarga merupakan tempat pembentukan sikap kepribadian anak dan perkembangan pembentukan dasar sikap serta pertumbuhan tubuh anak. ${ }^{17}$ Pengawasan orang tua dalam pergaulan yang dilakukan oleh anak, waktu puberitas, orang tua yang terlalu permisif dan memanjakan anaknya dari kecil mempengaruhi anak dalam berperilaku yang menyimpang. ${ }^{18}$

2. Faktor lingkungan masyarakat

Faktor lingkungan masyaratakat yang menyebabkan terjadinya kenakalan siswa antara lain: tidak stabilnya keadaan sosial, politik dan ekonomi, banyaknya film, dan buku bacaan yang tidak baik, merosotnya moral dan mental orang dewasa, kurangnya perhatian masyarakat dalam pendidikan anak. Lingkungan sosial budaya, dimana siswa itu berpijak sebagai mahluk sosial adalah masyarakat. Jika masyarkat itu baik maka pembentukan

${ }^{15}$ Zakiah Daradjat, Kesehatan Mental, (Jakarta: CV Haji Mas Agung, 1998), 111.

16 Loc. Cit. Firad Wijaya, 108.

17 Tohirin, Bimbingan dan Konseling di Sekolah atau Madrasah, (Jakarta: PT Raja Grapindo Persada, 2013), 109-110.

18 loc. Cit. Firad Wijaya, 109. 
kepribadian anak akan baik pula, sebaliknya bila lingkungan masyarakat itu tidak bak maka kepribadian anak juaga akan tidak baik.19

Peran masyarakat dan lingkungan dimana anak itu tinggal atau bergaul, pengaruh internet dan media sosial, pengaruh ajakan teman-temannya (sesama siswa) mempengaruhi perilaku anak.20 Peran lingkungan masyarakat berpengaruh pada sifat dan perilaku yang diterapkan anak dalam kesehariannya. ${ }^{21}$

\section{Strategi Guru BK dalam Mengatasi Kenakalan Siswa}

1. Strategi Pembelajaran

Strategi mengatasi kenakalan siswa melalui pembelajaran sebagai berikut: ${ }^{22}$

a. Pola Pembiasaan

1) Pembiasaan kegiatan kerohanian

Peningkatan kerohanian terhadap siswa merupakan suatu upaya yang dilakukan untuk memberikan pengarahan, bimbingan agar dengan cara sadar dan sukarela mau melaksanakan apa yang diperintahkan oleh Tuhan. Nilai-nilai religius ini dapat menjadi faktor pendorong untuk selalu berbuat baik, bukan hidup dalam kenakalan karena takut akan dosa yang akan ditanggungnya, menjadi panduan dalam menentukan pilihan hidup sesuai dengan ajaran agama yang dianut, mendorong, menekan dan menuntut seseorang untuk berbuat dan bertindak sesuai dengan nilai. ${ }^{23}$

19 Ibid.

${ }^{20}$ Nurul Qomariyah Ahmad, Asdiana dan Seni Jayatimar, “Upaya Guru Pendidikan Agama Islam dalam Menghadapi Kenakalan Remaja pada Masa Pubertas), Jurnal As-Salam, Vol. 3 No. 2 (Mei - Agustus 2019), 1 - 17

21 Tohirin, Bimbingan dan Konseling di Sekolah atau Madrasah, (Jakarta: PT Raja Grapindo Persada, 2013), 109-110.

22 Loc, cit. Muhamad Ghafur dan Dhuhaa Rohmawan, 95.

23 Chrisna Desni Tambuwun dan Richard Lomboan, "Strategi Guru Pendidikan Agama Kristen dalam Mengatasi Kenakalan Remaja Usia 15-17 Tahun di SMA Negeri I Amurang Timur." 


\section{Al-Isyrof \\ Jurnal Bimbingan Konseling Islam}

Institut Agama Islam Sunan Kalijogo Malang

P-ISSN 2622-674X / E-ISSN 2721-9585

Volume 2, Nomer 1 / Juni 2020

2) Memberikan gambaran atau pengantar materi yang diajarkan.

3) Materi yang ada dikembangkan dengan kejadian-kejadian saat itu berlangsung (contoh kejadian fenomenal).

4) Pemaparan kejadian lewat LCD, anak-anak ditugaskan untuk menganalisa (contoh video kenakalan remaja)

5) Teaching (siswa adalah guru), guru memberikan pengantar singkat dan materi pokok setelah itu anak-anak dibuat kelompok dan presentasi, tiap-tiap kelompok diberi materi untuk dikembangkan.

6) Pembiasaan sikap (setiap bertemu dewan guru mengucapkan salam dan berjabat jangan).

7) Melaksanakan kegiatan piket kelas sesuai jadwal yang ada.

8) Silaturrohmi ke dewan guru atau teman, menjenguk yang mengalami musibah.

9) Mengevaluasi presentasi siswa (memberi materi pokok setelah itu siswa disuruh presentasi terus dievaluasi).

10) Memberikan nasihat agar selalu menjaga citra dan almamater sekolah.

11) Memberikan perilaku yang menyenangkan.

12) Menghindari perilaku yang tidak mengenakkan.

b. Modeling

1) Memberi contoh yang baik.

Guru mengajarkan kejujuran terhadap siswa, maka siswa memperlakukan seperti yang dilakukan gurunya.

2) Berpakaian rapi.

Apabila guru berpakaian rapi, maka siswa mencontoh berpakaian rapi.

3) Berbicara yang sopan.

Apabila guru berbicara sopan, maka siswa mengikuti berbicara sopan.

4) Disiplin waktu.

Apabila guru disiplin waktu, maka siswa disiplin waktu. 


\section{Al-Isyrof \\ Jurnal Bimbingan Konseling Islam}

Institut Agama Islam Sunan Kalijogo Malang

P-ISSN 2622-674X / E-ISSN 2721-9585

Volume 2, Nomer 1 / Juni 2020

2. Strategi Tindakan Sekolah

Ada beberapa tindakan yang dapat dilakukan untuk mengatasi kenakalan siswa yaitu: ${ }^{24}$

a. Tindakan Preventif

Preventif berarti mencegah. Tindakan preventif merupakan suatu tindakan yang berfungsi untuk mencegah timbulnya kenakalan siswa. Tindakan preventif ini dilakukan secara sistematis, terencana dan terarah, untuk menjaga agar kenakalan itu tidak timbul.

Tindakan yang dilakukan guru BK adalah dengan mengadakan bimbingan secara klasikal didalam kelas selama dua jam pelajaran perminggu. Bimbingan yang diberikan berupa bimbingan karir, bimbinga sosial, dan bimbingan belajar. Selain itu tindakan lain yang dilakukan adalah dengan memberikan nasehat dan wawasan-wawasan yang bertujuan untuk mendidik siswa untuk memiliki kepribadian yang lebih baik. ${ }^{25}$

b. Tindakan Preserfatif

Tindakan preserfatif ini merupakan usaha guru BK untuk membina siswa yang bermasalah agar tidak melakukan kenakalan dikemudian hari. Upaya yang dilakukan oleh guru pembimbing adalah dengan mengarahkan siswa untuk mengikuti kegiatan ekstrakurikuler, dengan mengarahkan siswa untuk mengikuti kegiatan ektrakurikuler diharapkan siswa dapat lebih menggunakan waktu luangnya untuk melakukan kegiatan yang lebih positif. Selain kegiatan tersebut siswa juga diarahkan untuk mengikuti kegiatan ekstrakurikuler yang lain seperti PMR, pramuka, silat, marawis dan marching band.

24 Ibnudin, "Konsep Bimbingan dan Konseling dalam Mengatasi Kenakalan Siswa (Studi Kasus di MTs AlGozali Jatibarang Kabupaten Indramayu", Al-Afkar: Journal for Islamic Studies, Vol. 2, No. 2, (July 2019), 125-140; Sofyan S. Willis, Remaja dan Masalahnya, (Bandung: Alfabeta, 2014), 128.

25 Jamal Ma'mur Asmani, Kiat Mengatasi Kenakalan Remaja di Sekolah, (Yogyakarta: Buku Biru, 2012). 
c. Tindakan Kuratif

Tindakan kuratif merupakan suatu tindakan yang dilakukan oleh guru BK dalam mengembalikan kondisi siswa yang sudah melakukan kenakalan atau pelanggaran agar normal kembali. Fungsi BK yang bersifat kuratif ini berkaitan erat dengan upaya pemberian bantuan kepada siswa yang telah mengalami masalah, baik menyangkut aspek pribadi, sosial, belajar, maupun karir. Adapun upaya yang dilakukan adalah dengan memberi pengarahan dan wawasan kepada siswa terutama untuk meningkatkan keimanan, ketaqwaan, sehingga yang dilakukan oleh guru bimbingan dan konseling dalam ham ini adalah komunikasi dari hati ke hati dengan tujuan memperbaiki mental siswa.

Selain memberi pengarahan dan wawasan upaya lain yang dilakukan adalah dengan memantau terus perkembangan siswa yang sudah menjadi catatan pihak BK setelah diberlakukannya sanksi terhadap siswa yang melakukan pelanggaran sehingga diharapkan menimbulkan efek jera terhadap siswa. Bentuk-bentuk sanksi yang diberlakukan tidak mengarah pada hal yang negatif, tetapi mengarah pada tindakan positif dari efek sanksi tersebut.

Usaha kuratif dilakukan melalui memberikan pelatihan kepada para siswa untuk hidup teratur dan disiplin, memperbanyak program latihan peningkatan keterampilan, melakukan perubahan lingkungan tempat tinggal, memberikan fasilitas yang diperlukan untuk perkembangan jasmani dan rohani, menghilangkan atau menekan penyebab-penyebab timbulnya kenakalan.26

26 Ibid. 


\section{PENUTUP}

\section{Simpulan}

Hasil reviuw ini dapat disimpulkan sebagai berikut:

a. Bentuk-bentuk kenakalan siswa di sekolah teridiri dari 1) kenakalan kategori ringan seperti: membolos, ramai sewaktu pelajaran berlangsung, tidak mengerjakan tugas, seragam tidak lengkap, ke kantin saat pelajaran, bermain HP saat pelajaran, membantah guru dan orang tua, dll, 2). kenakalan kategori ringan seperti: mencuri, perkelahian, narkoba, asusila, dll.

b. Faktor yang mempengaruhi kenakalan siswa adalah 1) lingkungan keluarga dan 2) lingkungan pergaulan di masyarakat.

c. Strategi guru dalam mengatasi kenakalan siswa di sekolah yaitu 1) strategi pembelajaran berupa pembiasaan dan modeling, b) strategi tindakan berupa preventif, preservatif dan kuratif.

\section{Saran}

Solusi yang disarankan untuk pembinaan siswa dalam mengatasi kenakalan yaitu:

a. Menanamkan ajaran moral dan agama yang lebih mendalam. Hal ini dapat dilakukan dengan lebih meningkatkan kualitas pengajaran agama dengan menekankan pengajaran yang bermakna.

b. Menjalin kerjasama yang baik antara guru, kepala sekolah dan seluruh karyawan dalam melaksanakan peraturan sekolah sehingga berjalan sesuai aturan untuk pencegahan dan hukuman.

c. Menjalin kerjasama antara pihak sekolah dengan orang tua siswa yang terjalin melalui kunjungan guru ke rumah orang tua siswa atau pertemuan wali murid di sekolah. Kerjasama ini berorientasi pada perkembangan perilaku anak terutama ketika anak dalam lingkungan keluarga. Agar pihak keluarga semakin aktif dalam mendidik anak secara mental maupun sosial. 


\section{Al-Isyrof \\ Jurnal Bimbingan Konseling Islam}

Institut Agama Islam Sunan Kalijogo Malang

P-ISSN 2622-674X / E-ISSN 2721-9585

Volume 2, Nomer 1 / Juni 2020

\section{DAFTAR PUSTAKA}

Ahmad, Nurul Qomariyah., Asdiana dan Jayatimar, Seni. "Upaya Guru Pendidikan Agama Islam dalam Menghadapi Kenakalan Remaja pada Masa Pubertas", Jurnal As-Salam, Vol. 3 No. 2, (Mei - Agustus 2019), 9-17.

Asmani, Jamal Ma'mur. Kiat Mengatasi Kenakalan Remaja di Sekolah. Yogyakarta: Buku Biru, 2012.

Daradjat, Zakiah. Kesehatan Mental. Jakarta: CV Haji Mas Agung, 1998.

Ghafur, Muhamad dan Rohmawan, Dhuhaa. "Strategi Pembelajaran Afektif Guru PAI dalam Menanggulangi Kenakalan Siswa di SMK Brawijaya Kepung Kediri", Inovatif, Vol. 1, No. 2 (September 2015), 92-113.

Hadisi, La. "Pendidikan Agama Islam: Solusi Mengatasi Perilaku Menyimpang Siswa SMK Negeri 1 Kendari”, Al-Izzah, Vol. 8, No. 2, (November 2013), 124-146.

Ibnudin. "Konsep Bimbingan dan Konseling dalam Mengatasi Kenakalan Siswa (Studi Kasus di MTs Al-Gozali Jatibarang Kabupaten Indramayu)", Al-Afkar, Journal for Islamic Studies, Vol. 2, No. 2, (Juli 2019), 125-140.

Limon. Bimbingan dan Dasar-Dasar Pelaksanaannya. Jakarta: Rajawali, 2011.

Nata, Abudin. Perspektif Islam tentang Strategi Pembelajaran. Jakarta: Kencana, 2009.

Sarwono, Sarlito Wirawan. Psikologi Remaja. Jakarta: Rajawali Pres, 1991.

Surakmad, Winarno. Psikologi Pemuda. Bandung: Jenmars, 1997.

Tambuwun, Chrisna Desni dan Lomboan, Richard. "Strategi Guru Pendidikan Agama Kristen dalam Mengatasi Kenakalan Remaja Usia 15-17 Tahun di SMA Negeri I Amurang Timur."

Tohirin. Bimbingan dan Konseling di Sekolah atau Madrasah. Jakarta: PT Raja Grapindo Persada, 2013.

Wijaya, Firad. "Konseling Individual dalam Mengatasi Kenakalan Siswa di Madrasah Tsanawiyah Negeri 1 Yogyakarta", Al Tazkiah, Vol. 6, No. 2, (Desember 2017), 95-110.

Willis, Sofyan S. Remaja dan Masalahnya. Bandung: Alfabeta, 2014. 